\title{
New indicators for systematic assessment of aortic morphology: a narrative review
}

\author{
Jingyang Luan ${ }^{1 \#}$, Le Mao ${ }^{1 \#}$, Ziqing Zhu' ${ }^{2}$, Weiguo Fu' ${ }^{1}$, Ting Zhu ${ }^{1}$ \\ ${ }^{1}$ Department of Vascular Surgery, Zhongshan Hospital, Fudan University, Shanghai, China; ${ }^{2}$ Department of Psychology, School of Public Health, \\ Southern Medical University, Guangzhou, China \\ Contributions: (I) Conception and design: J Luan, L Mao; (II) Administrative support: L Mao, T Zhu, W Fu, L Mao; (III) Provision of study \\ materials or patients: Z Zhu, J Luan; (IV) Collection and assembly of data: J Luan, L Mao; (V) Data analysis and interpretation: J Luan, L Mao; (VI) \\ Manuscript writing: All authors; (VII) Final approval of manuscript: All authors. \\ \#These authors contributed equally to this work. \\ Correspondence to: Ting Zhu, MD, PhD. Department of Vascular Surgery, Zhongshan Hospital, Fudan University, 180 Fenglin Road, Shanghai \\ 200032, China. Email: zhutingfudan@163.com.
}

\begin{abstract}
In order to prevent the occurrence of aortic adverse events in ascending thoracic aortic aneurysm patients, preventive surgery is the sole option in case of large aneurysm. Identifying high-risk patients timely and accurately requires effective predictive indicators of aortic adverse events and accurate risk stratification thresholds. Absolute diameter measured after a single imaging examination, which has been used as the predictive indicator for decades, has been proved to be ineffective for risk stratification in moderately dilated aorta. Previously, new indicators combining absolute diameters with personalized parameters have been reported to show better predictive power of aortic adverse events than absolute diameters by correcting the effect of these parameters on the diameters. Meanwhile, combining three-dimensional parameters to formulate risk stratification thresholds not only may characterize the aortic risk morphology more precisely, but also predict aortic adverse events more accurately. These new indicators may provide more systematic assessment methods of patients' risk, formulate more personalized intervention strategies for ascending thoracic aortic aneurysm patients, and also provide a basis for researchers to develop more accurate and effective risk thresholds. We also highlight that the algorithm obtained by combining multiple indicators may be a better choice compared with single indicator, but this still requires the support of more evidence. Due to the particularity of syndromic aortic disease, whether these new indicators can be used for its risk stratification is still uncertain. Therefore, the scope of this manuscript does not include this kind of disease.
\end{abstract}

Keywords: Ascending thoracic aortic aneurysm (ATAA); aortic morphology; predictive indicator

Submitted Aug 23, 2020. Accepted for publication Nov 15, 2020.

doi: $10.21037 /$ jtd-20-2728

View this article at: http://dx.doi.org/10.21037/jtd-20-2728

\section{Introduction}

Ascending thoracic aortic aneurysm (ATAA), with an incidence about 10 per 100,000 patient-years, is a lifethreatening disease that is associated with increased risk of aortic adverse events (AAEs) (1,2). Clinically, AAEs include rupture, aortic dissection (AD) and mortality. For ATAA patients with high risk of developing AAEs, the mortality rate following emergency surgery is fairly high (16-59\%) $(1,3)$. Therefore, for high-risk ATAA patients, preventive surgery is often performed before AAEs occur and in such cases the mortality rate drops to $3-9 \%(1,3,4)$. Although the effectiveness of preventive surgery has improved in recent years, how to accurately identify high-risk patients who are suitable for preventive surgery (the risk of AAEs occurrence exceeds the risk of surgery) remains a significant challenge for surgeons (5).

The purpose of this study is to review the indicators proposed in current studies that may help to identify 
patients at high risk of AAEs and suitable for applying intensive surveillance and early interventions. We also highlight that the algorithm obtained by combining multiple indicators may be a better choice compared with single indicator, but this still requires more the support of evidence $(6,7)$. We present the following article in accordance with the Narrative Review Checklist (available at http://dx.doi.org/10.21037/jtd-20-2728).

\section{Methods}

A literature search was conducted using MEDLINE, Embase, Web of Science, PubMed from January 2000 to June 2020. The search terms included "ascending thoracic aortic aneurysm", "ATAA", "morphology", "geometry", "morphological" and "geometric". These terms were combined using the Boolean operator AND or OR. After identifying relevant studies, we expanded the electronic search using the "related articles" function in PubMed. The reference lists of related studies were manually screened to obtain additional studies. If the unpublished data reported sufficient data, they were considered for inclusion to reduce the publication bias, and the primary authors were contacted for missing data.

Criterions for inclusion were as follows: the study (I) reported at least one morphological indicator predicting AAEs in patients with ATAA; (II) consisted of 10 or more patients; (III) clearly defined the AAEs; (IV) described the detection methods of AAEs in patients with ATAA.

Criterions for exclusion were as follows: (I) non-English language; (II) animal and laboratory studies; (III) letters to editors and commentaries; (IV) systematic reviews and meta-analysis; (V) case reports; (VI) conference abstracts without extractable data; (VII) included only other acute aortic syndromes (e.g., $\mathrm{AD}$, penetrating aortic ulcer).

\section{Discussion}

\section{Absolute aortic diameter as an indicator}

Absolute aortic diameter is an essential morphological indicator in AAEs prediction (8). Previous studies demonstrated that the risk of AAEs increased when the diameter of the ascending aorta reached $6 \mathrm{~cm}$; therefore, $5.5 \mathrm{~cm}$ is recommended as a threshold for preventive surgery in current guidelines (2). However, in patients with ATAA, most AAEs occur in the aorta with diameters less than $5.5 \mathrm{~cm}$, which is considered as the aortic size paradox
(9-12). On the one hand, the phenomenon is probably due to the bell-shaped curve of the aortic diameter distribution in the general population. Specifically, the number of people with aortic diameters less than $5.5 \mathrm{~cm}$ is much larger than that of people with a diameter greater than $5.5 \mathrm{~cm}(13,14)$. On the other hand, this may be due to heterogeneity among the studies of measurement methods used to confirm the threshold of $5.5 \mathrm{~cm}$ (15-17). Although the preventive surgery threshold should be applicable to patients before AAEs onset, most studies only analyzed the aorta of patients who had already developed AAEs, and there are few studies comparing the aortic diameter before and after the occurrence of AAEs $(6,12,18,19)$. Previous study reported an increment of at least $32 \%$ in the average mid-ascending aortic diameter after $\mathrm{AD}$ occurrence, with a value of $13 \pm 7 \mathrm{~mm}$ (12). As a result of this $\mathrm{AD}$ primed aortic dilatation, the aortic diameter, which should be recommended as risk stratification threshold, may be less than $5.5 \mathrm{~cm}(20,21)$. Secondly, the diameters of the different segments of the aorta are different, and there is no uniform standard for which segment should be used for setting the threshold (4,15,19,22-24). Thirdly, optimal imaging methods for ATAA include echocardiography, computed tomography (CT) and magnetic resonance imaging, which are complementary but not competitive $(6,24,25)$. There are slight differences in the diameter data obtained by the three methods, which leads to differences in findings among studies that use different imaging methods (22). Meanwhile, the methods of measuring the diameter vary from study to study (26). Currently, AAEs prediction is based on traditional data analysis methods, including manual axial, coronal, and sagittal image analysis $(3,19,27)$. These risk stratification thresholds are not suitable for patients using the centerline measurement technique, which usually obtains lower aortic diameter $(28,29)$. Thus, as the centerline method increasingly used, it may be necessary to "left-shift" the thresholds (30). Furthermore, there is also a method of calculating the diameter based on the circumference to minimize the influence of the non-circular aorta $(7,31)$. The above evidence suggests that a unified acquisition protocol and general morphological parameters should be developed to eliminate heterogeneity caused by different measurement methods (22).

For the reasons outlined above, we believe that the risk stratification thresholds in current guidelines are not reliable (30). In addition to the heterogeneity in the formation of these thresholds, there are still several issues associated with the application of diameter alone as a single indicator (6,32). Firstly, when comparing the median 
diameters of non-AAE, post-AAEs and pre-AAEs aortas, the diameter ranges of these three groups substantially overlap, which explains why there is suboptimal discrimination between non-AAEs and AAEs aortas based on diameter alone (33). Secondly, diameter alone does not account for all the relevant factors that contribute to aortic geometry, such as the irregular, elliptical shape of the aorta, and the threedimensional (3D) process of aortic growth $(10,34)$.

In conclusion, on a populational level, the aortic diameter may be useful to predict poor prognosis, but it is not sufficient to identify particular patients who are at risk of AAEs. For this reason, investigations are underway to explore new predictive indicators to help clinicians accurately identify ATAA patients in a timely manner who are candidates for preventive surgery.

\section{New indicators combining aortic diameter and personalized parameters}

Aortic diameter is modulated by several personalized parameters such as height, gender, age, lifestyle, body size, hypertension, genetic factors, bicuspid aortic valve (BAV) and sleep apnea $(6,23,25,35-44)$. Due to the correlation between diameter and these parameters, it may not be appropriate to classify patients with the same diameter but with different personalized parameters into the same risk category (6). Therefore, we discuss new indicators that combine aortic diameter with personalized parameters and compare their efficiency in AAEs prediction.

\section{Diameter height index (DHI)}

Previous studies reported the correlation between height and aortic diameter, which are both affected by genetics. Importantly, it is not reasonable to use the same risk stratification threshold in ATAA patients of different heights (38). Many studies have adopted a new predictive indicator called DHI by indexing height to diameter, which is known to be consistent in people of different heights (2,27,34,38,45-48). Abnormal DHI was highly correlated with increased long-term cardiovascular mortality, which illustrates its suitability as predictor of AAEs $(34,47)$. Previous studies have used DHI $=2.4 \mathrm{~cm} / \mathrm{m}$ as the risk stratification threshold, and found that patients with DHI above this threshold have significantly higher probability of surgical intervention than those below $(\mathrm{P}<0.001)(2)$. Moreover, DHI can help to stratify diameter indicators in moderately dilated aorta $(4.5-5.5 \mathrm{~cm})$ and identify high-risk patients who may develop AAEs, which remains a grey area in the current guidelines $(34,46,47)$. Among patients with moderately dilated aorta, $44 \%$ had abnormal DHI, and this population accounted for $78 \%$ of long-term deaths (47). Among patients with a BAV as well as a moderately dilated aorta, patients with abnormal DHI accounted for $70 \%$ of overall mortality (46). In another study, ATAA patients were further divided into $45-50$ and $50-55 \mathrm{~mm}$ groups. It was reported that $49.1 \%$ of patients in the $45-50 \mathrm{~mm}$ group and $98.5 \%$ in the $50-55 \mathrm{~mm}$ group had abnormal DHI (34). This shows that combining height and aortic diameter to create new predictive indicators can effectively categorize patients with moderately dilated aorta. In patients with genetically mediated aneurysms, including suspected familial aortic syndromes, BAV and Marfan syndrome (MFS), DHI is already used as additional criterion to warrant elective aortic repair $(8,38,45,49)$. This further illustrates the feasibility of DHI as a predictive indicator of risk stratification in patients with ATAA.

\section{Aortic size index (ASI)}

Many studies focused on creating nomograms for aortic diameter prediction based on body surface area (BSA), which have already been adopted in guidelines $(50,51)$. BSA, which accounts for both body size and height, is known to correlate with aortic diameter $(25,39,52)$. Therefore, recent studies reported a new indicator named ASI, which is the aortic diameter indexed by BSA for AAEs prediction (27). For ATAA patients with ASI less than $2.75 \mathrm{~cm} / \mathrm{m}^{2}$, between $2.75-4.25 \mathrm{~cm} / \mathrm{m}^{2}$ and above $4.25 \mathrm{~cm} / \mathrm{m}^{2}$, the yearly incidence of AAEs is $4 \%, 8 \%$ and $20-25 \%$, respectively (27). ASI has been shown to be a better predictor for AAEs than simple aortic diameter by all analytic methods, although there is still ongoing debate around the merits of DHI and ASI $(2,27)$. Some studies reported that diameter is associated with height but not with BSA, whereas others reached the opposite conclusion, which is probably due to heterogeneity between studies $(24,39,51)$. Moreover, most studies reported that DHI yields more satisfactory results for AAEs prediction in ATAA patients than ASI, as evidenced by a higher area under curve (AUC) $(2,48)$. This is most likely because height is more stable compared with body size parameters, which do not significantly fluctuate throughout adulthood (6). At the same time, compared with BSA, height is easier to measure clinically, and errors can be eliminated by BSA calculation (45).

\section{Age}

Previous studies proposed morphological indicators 
according to different age groups to predict type B aortic dissection, with larger threshold values for elderly patients, whereas studies in patients with ATAA are insufficient (40). Risk stratification thresholds should be adjusted according to age because aorta morphology changes with age $(8,25,33,40,53)$. In particular, the aortic diameter in people under 15 years of age increases at the fastest rate. From the age of 15 years, the diameter growth rate slows down to 1.3 and $1.2 \mathrm{~mm}$ per decade for males and females, respectively (54). Moreover, most aortic geometric variables, including arch morphology, aortic circumference, thickness, and aortic length, are age-dependent $(33,40-42,53)$. In addition to the morphology of the aorta, as age increases, changes also occur in microstructural components including collagen, elastin and smooth muscle cells $(26,55)$. These components change in each tunica of the aortic wall both in quantity and organization (56). As older patients exhibit a weaker wall under delamination but not tensile strength, they are more prone to dissection propagation (43). Although this strong evidence supports the idea that the ATAA risk stratification thresholds should be adjusted for patients of different ages, there is currently no model in place and this remains an important direction for future research.

\section{Gender}

Previous studies suggested that different risk stratification thresholds should be applied separately for men and women. The main reason is that in ATAA patients with AAEs, aortic diameter in women is often smaller than in men, which may be due to inherent physiological differences $(19,24,39,44,54,57)$. The mean diameter of the ascending aorta is $38 \pm 4$ and $35 \pm 3 \mathrm{~mm}$ in males and females, respectively. For men, the percentage of ascending aorta diameters greater than $40 \mathrm{~mm}$, greater than $45 \mathrm{~mm}$, and greater than $50 \mathrm{~mm}$ is $18.9 \%, 2.2 \%$, and $0.2 \%$, respectively, and $5.9 \%, 0.5 \%$, and $0 \%$, respectively in women (58). Some studies suggest that these differences can be partly explained by body size (males tend to have larger BSA) (58). However, many studies have shown that even if BSA is adjusted, there is still a gender difference in aortic diameter $(19,57,58)$. Specifically, the average aorta of older men is larger than that of women of similar ages, but the difference between young men and women is small $(25,54)$. In addition, female patients with ATAA have a higher MMP (matrix metalloproteinases)/TIMP (tissue inhibitor of metalloproteinase) expression ratio (probably due to estrogen) (59). MMP can degrade extracellular matrix components in the aorta, resulting in aortic remodeling, which in turn increases aortic stiffness $(60,61)$. Aortic stiffness is associated with accelerated aneurysm growth, which is a high-risk factor for AAEs occurrence (guidelines recommend preventive surgery when aneurysm growth reaches $>0.5 \mathrm{~cm} /$ year) $(8,62)$.

Due to these differences between genders, whether morphologically or biologically, it is unreasonable for men and women to be subject to the same risk stratification thresholds. Otherwise, this may lead to a considerable proportion of women with AAEs who may not undergo preventive surgery in a timely manner (62). As a result, the mortality rate of female ATAA patients is $40 \%$ higher than males, and the risk of dissection or rupture is tripled (19). However, although there is sufficient evidence to support the use of sex-specific risk stratification thresholds, specific protocols that are verified for aneurysm surveillance and treatment in male and female ATAA patients are yet to be developed $(58,62)$.

\section{Non-syndromic ATAA}

It has been reported that $20 \%$ of TAA patients have a first- degree relative whose thoracic aorta is dilated, which shows the important role of genes in TAA (35). In contrast to syndromic ATAA, some families exhibit abnormalities limited to the cardiovascular system without physical features of connective tissue disorders (63). These conditions are called non-syndromic ATAA include familial thoracic aortic aneurysm and dissections (FTAAD), familial thoracic aortic aneurysm and BAV with aneurysm (63). The non-syndromic ATAA related genes included ACTA2, MYH11, MYLK and PRKG1, which encode components of the smooth muscle contractile apparatus (64-67).

It has been reported that non-syndromic ATAA tend to grow at a higher rate even compared with MFS patients, which highlights the need for different risk stratification thresholds for non-syndromic ATAA patients (35). Previous studies have focused on assessing relationships between candidate genes and ATAA to facilitate daily monitoring of the aorta, early intervention of aortic disease and family cascade screening $(68,69)$. As technology advances and the cost of DNA sequencing continues to decrease, the use of ATAA-related genetic testing is expected to gradually increasing clinical practice.

\section{Hypertension}

It was traditionally considered that hypertension would accelerate the rupture of elastin fibers in the aorta, causing the proximal aortic dilation $(70,71)$. However, as previous 
studies have shown, compared with the diameter prediction model established by height, body size, age, and gender, the incremental effect of hypertension is much smaller (39,72-74). Another study divided patients with hypertension into four subgroups, including prehypertension, systolicdiastolic, isolated diastolic and isolated systolic. However, there were no significant difference in aortic root diameter between the subgroups and normotensive individuals after adjusting age and BSA (36). As whether hypertension will cause aortic dilatation is still unclear, no studies have proposed the revision of risk stratification thresholds for hypertension patients.

\section{Other morphological indicators}

As mentioned above, a single diameter, as a twodimensional (2D) indicator in the horizontal direction, is insufficient to describe the complex $3 \mathrm{D}$ shape of the entire aorta (47). Previous studies have proposed many $3 \mathrm{D}$ indicators (e.g., diameter, length, volume, curvature, arch morphology and angulation) for characterizing the geometric complexity of the aorta (33). At present, the acquisition of these $3 \mathrm{D}$ indicators is mostly processed by $3 \mathrm{D}$ post-processing technology based on computer tomography angiography (CTA) $(75,76)$. Although $3 \mathrm{D}$ parameter acquisition depends on $3 \mathrm{D}$ reconstruction of the aorta (which more or less limits the application), the advancement of modern acquisition technologies has made it increasingly convenient $(77,78)$. Meanwhile, echocardiography, which has high repeatability and no nephrotoxicity from contrast agents, has been proven to have the potential to measure 3D parameters (79). Previous study measured length from aortic annulus to the most cranial part of visible aorta with transthoracic 2D echocardiography (80). Another study also proposed an algorithm for aortic root $3 \mathrm{D}$ modeling based on 2D echocardiography by a computer-aided design software (81). Such technological progress makes 3D indicators expected to be widely used. Therefore, numerous studies have focused on $3 \mathrm{D}$ parameters to confirm morphological differences other than diameter between the non-AAEs aorta and AAEs aorta (82). This shows that when formulating risk stratification thresholds, we should consider combining $3 \mathrm{D}$ parameters to characterize aortic risk morphology more precisely and improve the accuracy of diagnosis and prognosis (33). We will introduce some indicators that have proven to show effectiveness of predicting AAEs, and other indicators that may be useful are summarized in the Table 1.

\section{Aortic length}

As mentioned above, previous descriptions of aortic morphology always focused on horizontal indicators such as diameter (6). However, the observation that the entrance of the aortic dissection mostly extends in a circumferential direction could be explained by decreased longitudinal elasticity due to aortic elongation $(53,88)$. Meanwhile, a previous study also showed that the length of the AAEs aorta processed from $3 \mathrm{D}$ reconstruction based on CTA is significantly larger than the non-AAEs aorta $(7,78)$. These findings led to further investigation into the correlation, if any, between aortic length and the risk of AAEs (Figure 1) $(7,78)$. It has been further reported that each centimeter increase in the length of the aorta carries a 5 -fold risk of AAEs occurrence, and the probability of AAEs in the aorta with a length greater than $13 \mathrm{~cm}$ is 12.4 times higher than that of less than $9 \mathrm{~cm}(6,31)$. This correlation is independent of the increase in diameter: some aortas only have mild dilatation, whereas the length increases sharply (7). This shows the rationality of aortic length as a predictive indicator, and studies have further proved that the sensitivity of aortic length as a predictor is sevenfold higher than for diameter. The possible reasons why length is suitable for AAEs prediction are as follows: firstly, aortic elongation reduces the thickness of the aortic wall and causes elastin fiber fragmentation, further increasing aortic stiffness, which is manifested by a significant increase in aortic pulse wave velocity and brachial/aortic pulse pressure ratio (53). Secondly, as the length of the aorta increases, asymmetrical changes in the aortic morphology occur simultaneously, which disrupts the blood flow pattern, resulting in activated mechanical transduction pathways $(7,31,53)$. This in turn affects the structure and function of aortic wall cells (89). Moreover, unlike the diameter, the length of the aorta does not change much before and after the occurrence of AAEs, with a slight increase of just $3 \%$, which reduces the study heterogeneity when developing aortic length thresholds (6).

However, for single indicators, regardless of length and diameter, there are still overlaps in the distribution of AAEs aorta and non-AAEs aorta, suggesting the need for indicators which comprehensively reflect aortic morphology (33). A previous study calculated the length and diameter of the aorta as an arithmetic sum and created a new indicator called aortic height index (AHI) (diameter height index + length height index) (6). Importantly, the AUC of AHI for AAEs prediction was higher than for diameter (6). Moreover, for moderately dilated aorta where diameter is not an optimal indicator, the annual rate of AAEs increases proportionally 
Table 1 other parameters in 3D model

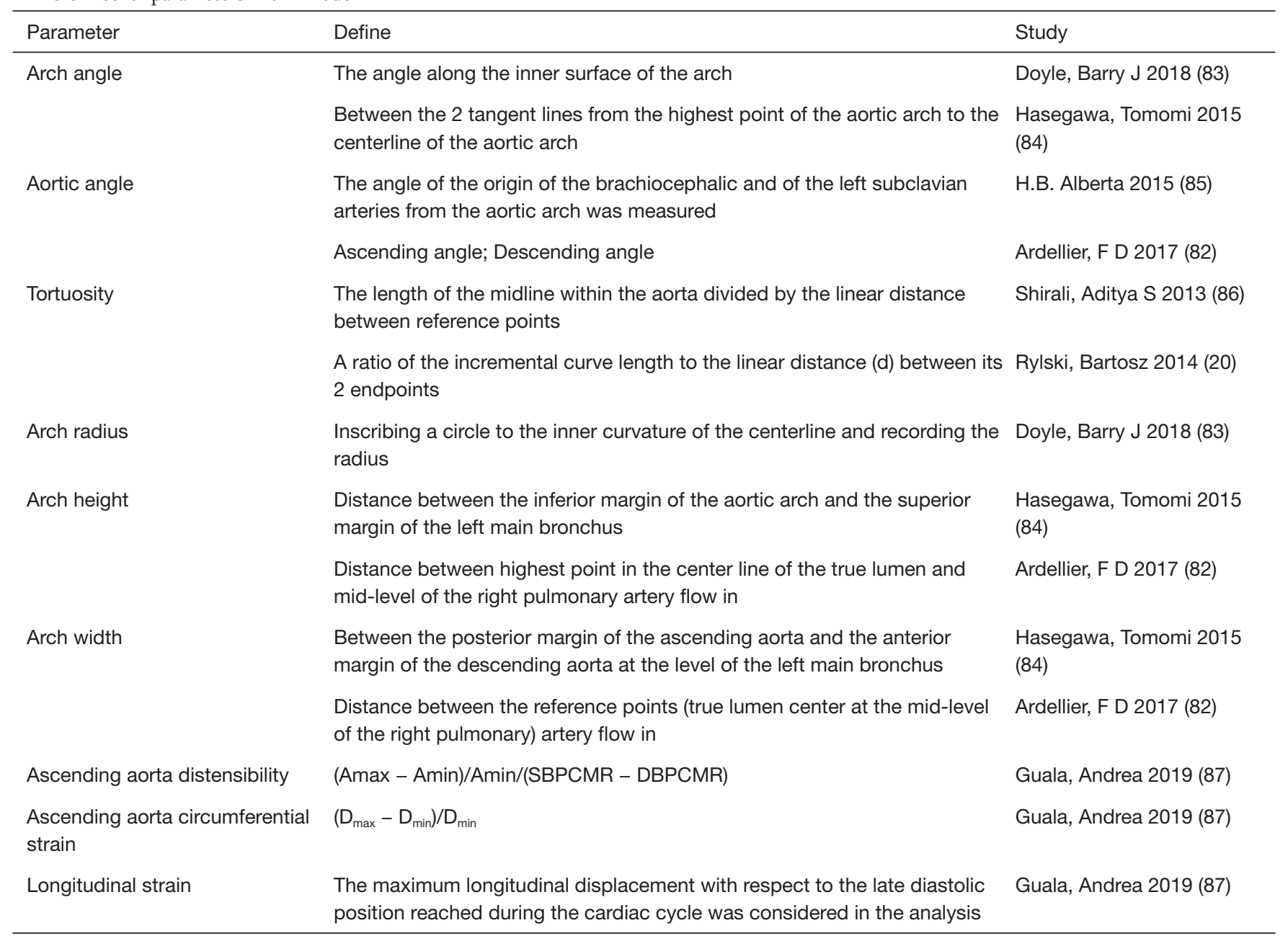

$D_{\max } \& D_{\min }$ : the maximum (systolic) and minimum (diastolic) diameters of the aorta.

with increasing AHI (6). Another study proposed a score that combines aortic length and diameter to predict the risk of AAEs. The score defines a diameter $\geq 55 \mathrm{~mm}$ as 2 points, a diameter between 45 and $54 \mathrm{~mm}$ as 1 point, and a centerline length $\geq 120 \mathrm{~mm}$ as 1 point (7). When the total score is greater than 2 points, the preventive surgery is recommended. At least $23.5 \%$ of pre-TAD patients had a positive score (sensitivity $=0.24$ ), and the identifiable preTAD patients were at least twice as many as when diameter alone is used as a risk indicator. The above evidences showed the superiority of algorithms obtained by combining multiple indicators, and the establishment and proof of these algorithms may become the future research direction.

\section{Arch tortuosity}

Previous studies have found that patients with aortic disease have extremely high arch tortuosity compared with healthy controls, and there are often fewer cardiovascular risk factors when AAEs occur in patients with high arch tortuosity (Figure 1) (7). On the one hand, the extremely high arch tortuosity results in increased systolic wave reflection in the arch, which in turn increases wall stress and causes structural changes in the aortic wall (increased stiffness and decreased compliance), finally leading to the occurrence of AAEs $(77,90-93)$. On the other hand, high arch tortuosity also reflects the hemodynamic stress caused by progressive structural damage in the vascular media and further pathologic remodeling (77).

Based on these factors, we believe that aortic arch tortuosity can be used as a predictive indicator for AAEs occurrence. In addition, the continuous advancement of CTA-based 3D reconstruction technology makes it possible 


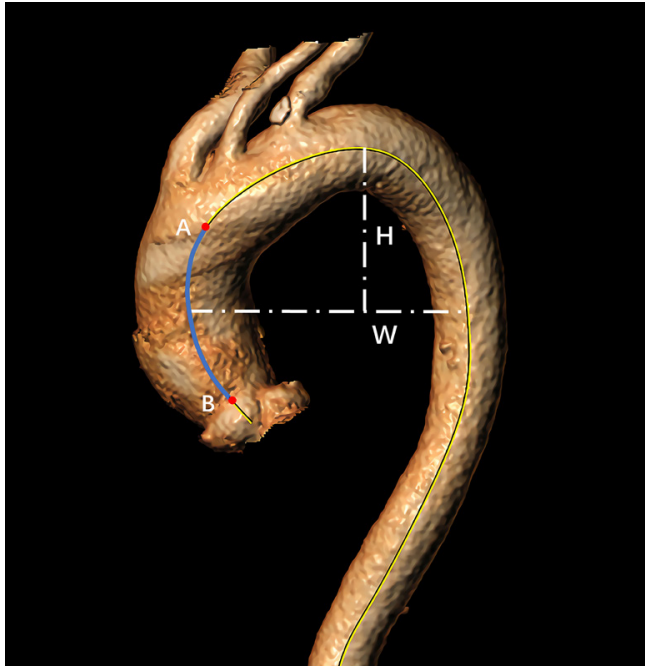

Figure 1 Methodology of the aortic 3D indicator measurements. The ascending aorta length was defined as the centerline distance between the origin of the brachiocephalic trunk (A) and the sinotubular junction (B). The most commonly used method to define arch tortuosity is height-to-width ratio. Width of the aortic $\operatorname{arch}(\mathrm{W})$ was measured as the maximal horizontal distance between the midpoints of the ascending and descending aorta close to the axial plane going through the right pulmonary artery. Height of the aortic $\operatorname{arch}(\mathrm{H})$ was measured as the maximal vertical distance between $W$ and the highest midpoint of the aortic arch.

to quantify the aortic arch tortuosity (76). However, there is great heterogeneity among studies with regards to definitions of arch tortuosity $(92,94,95)$. Meanwhile, the anatomical sites that measure arch tortuosity are not the same between different studies and no protocols have been validated in a robust fashion $(86,94,95)$. To fully understand the correlation between arch tortuosity and the occurrence of AAEs, validated protocols for defining arch tortuosity are required. A previous study proposed a method to determine aortic arch tortuosity based on 2D images, which is easy to apply clinically and has the potential to be used as a standard definition protocol in the future (77).

\section{Others}

Although the focus of this article is on aortic morphological parameters, we also fully recognize the need to develop and verify non-morphological parameters, such as biomechanical indicators (6). A large number of studies have proposed indicators for abdominal aortic aneurysms including wall stress rupture potential index, numerically predicted wall stress, severity parameter and finite element analysis rupture index (96-99). Less data are currently available on the mechanical properties of ATAA (100-102). In recent years, studies have also suggested that ATAA can be identified by whole blood analysis before imaging, and that plasma signatures for certain proteins (such as collagen) can not only identify ATAA patients but also stratify them into etiologic subtypes, which is important for personalized treatment $(32,103)$.

\section{Conclusions}

The accurate and timely identification of high-risk patients requires effective predictive indicators of AAEs and accurate risk stratification thresholds. Compared with a single diameter, whether that be the combination of absolute diameter and personalized parameters, or the combination of $3 \mathrm{D}$ parameters to formulate risk stratification thresholds, models based on combined indicators show better accuracy in AAEs prediction. We also highlight that the algorithm obtained by combining multiple indicators may be a better choice compared with single indicator, but this still requires the support of more evidence.

\section{Acknowledgments}

Funding: This work was supported by a grant from the National Natural Science Foundation of China (No. 51576049).

\section{Footnote}

Reporting Checklist: The authors have completed the Narrative Review Checklist. Available at http://dx.doi. org/10.21037/jtd-20-2728

Peer Review File: Available at http://dx.doi.org/10.21037/jtd20-2728

Conflicts of Interest: All authors have completed the ICMJE uniform disclosure form (available at http://dx.doi. org/10.21037/jtd-20-2728). The authors have no conflicts of interest to declare.

Ethical Statement: The authors are accountable for all aspects of the work in ensuring that questions related to the accuracy or integrity of any part of the work are appropriately investigated and resolved. 
Open Access Statement: This is an Open Access article distributed in accordance with the Creative Commons Attribution-NonCommercial-NoDerivs 4.0 International License (CC BY-NC-ND 4.0), which permits the noncommercial replication and distribution of the article with the strict proviso that no changes or edits are made and the original work is properly cited (including links to both the formal publication through the relevant DOI and the license). See: https://creativecommons.org/licenses/by-nc-nd/4.0/.

\section{References}

1. Clouse WD, Hallett JW, Schaff HV, et al. Improved prognosis of thoracic aortic aneurysms. A populationbased study. JAMA1998;280:1926-9.

2. Saeyeldin A, Zafar MA, Li Y, et al. Decision-making algorithm for ascending aortic aneurysm: Effectiveness in clinical application? J Thorac Cardiovasc Surg 2019;157:1733-45.

3. Coady MA, Rizzo JA, Hammond GL, et al. What is the appropriate size criterion for resection of thoracic aortic aneurysms? J Thorac Cardiovasc Surg 1997;113:476-91.

4. Elefteriades JA. Natural history of thoracic aortic aneurysms: Indications for surgery, and surgical versus nonsurgical risks. Ann Thorac Surg 2002;74:S1877-80; discussion S1892-8.

5. Evangelista A. Familial nonsyndromic thoracic aortic aneurysms: Unraveling the mystery and defining longterm outcome. J Am Coll Cardiol 2016;67:627-9.

6. Wu J, Zafar MA, Li Y, et al. Ascending Aortic Length and Risk of Aortic Adverse Events: The Neglected Dimension. J Am Coll Cardiol. 2019;74:1883-94.

7. Krüger T, Sandoval Boburg R, et al. Aortic elongation in aortic aneurysm and dissection: The Tübingen Aortic Pathoanatomy (TAIPAN) project. Eur J Cardiothorac Surg 2018;54:26-33.

8. Hiratzka LF, Bakris GL, Beckman JA, et al. 2010 ACCF/AHA/AATS/ACR/ASA/SCA/SCAI/SIR/STS/ SVM Guidelines for the Diagnosis and Management of Patients With Thoracic Aortic Disease. J Am Coll Cardiol 2010;55:e27-129.

9. Pape LA, Tsai TT, Isselbacher EM, et al. Aortic diameter $\geq 5.5 \mathrm{~cm}$ is not a good predictor of type A aortic dissection: Observations from the International Registry of Acute Aortic Dissection (IRAD). Circulation 2007;116:1120-7.

10. Adriaans BP, Wildberger JE, Westenberg JJM, et al. Predictive imaging for thoracic aortic dissection and rupture: moving beyond diameters. Eur Radiol
2019;29:6396-404.

11. Kim JB, Spotnitz M, Lindsay ME, et al. Risk of Aortic Dissection in the Moderately Dilated Ascending Aorta. J Am Coll Cardiol 2016;68:1209-19.

12. Rylski B, Blanke P, Beyersdorf F, et al. How does the ascending aorta geometry change when it dissects? J Am Coll Cardiol 2014;63:1311-9.

13. Elefteriades JA, Ziganshin BA, Rizzo JA, et al. Indications and imaging for aortic surgery: Size and other matters. J Thorac Cardiovasc Surg 2015;149:S10-3.

14. Paruchuri V, Salhab KF, Kuzmik G, et al. Aortic Size Distribution in the General Population: Explaining the Size Paradox in Aortic Dissection. Cardiology 2015;131:265-72.

15. Gagné-Loranger M, Dumont É, Voisine P, et al. Natural history of 40-50 mm root/ascending aortic aneurysms in the current era of dedicated thoracic aortic clinics. Eur J Cardiothorac Surg 2016;50:562-6.

16. Park KH, Chung S, Kim DJ, et al. Natural history of moderately dilated tubular ascending aorta: Implications for determining the optimal imaging interval. Eur J Cardiothorac Surg 2017;51:959-64.

17. Guo MH, Appoo JJ, Saczkowski R, et al. Association of Mortality and Acute Aortic Events With Ascending Aortic Aneurysm: A Systematic Review and Meta-analysis. JAMA Netw Open 2018;1:e181281.

18. Coady MA, Rizzo JA, Hammond GL, et al. Surgical intervention criteria for thoracic aortic aneurysms: A study of growth rates and complications. Ann Thorac Surg 1999;67:1922-6.

19. Davies RR, Goldstein LJ, Coady MA, et al. Yearly rupture or dissection rates for thoracic aortic aneurysms: Simple prediction based on size. Ann Thorac Surg 2002;73:17-27.

20. Rylski B, Branchetti E, Bavaria JE, et al. Modeling of predissection aortic size in acute type A dissection: More than $90 \%$ fail to meet the guidelines for elective ascending replacement. J Thorac Cardiovasc Surg 2014;148:944-948.e1.

21. Mansour AM, Peterss S, Zafar MA, et al. Prevention of Aortic Dissection Suggests a Diameter Shift to a Lower Aortic Size Threshold for Intervention. Cardiology 2018;139:139-46.

22. Asch FM, Yuriditsky E, Prakash SK, et al. The Need for Standardized Methods for Measuring the Aorta. JACC Cardiovasc Imaging 2016;9:219-26.

23. Oladokun D, Patterson BO, Sobocinski J, et al. Systematic Review of the Growth Rates and Influencing Factors in Thoracic Aortic Aneurysms. Eur J Vasc Endovasc Surg 
2016;51:674-81.

24. Hager A, Kaemmerer H, Rapp-Bernhardt U, et al. Diameters of the thoracic aorta throughout life as measured with helical computed tomography. J Thorac Cardiovasc Surg 2002;123:1060-6.

25. Wolak A, Gransar H, Thomson LEJ, et al. Aortic Size Assessment by Noncontrast Cardiac Computed Tomography: Normal Limits by Age, Gender, and Body Surface Area. JACC Cardiovasc Imaging 2008;1:200-9.

26. Lin FY, Devereux RB, Roman MJ, et al. Assessment of the thoracic aorta by multidetector computed tomography: Age- and sex-specific reference values in adults without evident cardiovascular disease. J Cardiovasc Comput Tomogr 2008;2:298-308.

27. Davies RR, Gallo A, Coady MA, et al. Novel measurement of relative aortic size predicts rupture of thoracic aortic aneurysms. Ann Thorac Surg 2006;81:169-77.

28. Rengier F, Weber TF, Giesel FL, et al. Centerline analysis of aortic CT angiographic examinations: Benefits and limitations. AJR Am J Roentgenol 2009;192:W255-63.

29. Han SM, Elsayed RS, Ham SW, et al. Comparison of intravascular ultrasound- and centerline computed tomography-determined aortic diameters during thoracic endovascular aortic repair. J Vasc Surg 2017;66:1184-91.

30. Ziganshin BA, Zafar MA, Elefteriades JA. Descending threshold for ascending aortic aneurysmectomy: Is it time for a "left-shift" in guidelines? J Thorac Cardiovasc Surg 2019;157:37-42.

31. Krüger T, Oikonomou A, Schibilsky D, et al. Aortic elongation and the risk for dissection: The Tübingen Aortic Pathoanatomy (TAIPAN) project. Eur J Cardiothorac Surg 2017;51:1119-26.

32. Ikonomidis JS, Ivey CR, Wheeler JB, et al. Plasma biomarkers for distinguishing etiological subtypes of thoracic aortic aneurysm disease. J Thorac Cardiovasc Surg 2013;145:1326-33.

33. Krüger T, Forkavets O, Veseli K, et al. Ascending aortic elongation and the risk of dissection. Eur J Cardiothorac Surg 2016;50:241-7.

34. Masri A, Kalahasti V, Svensson LG, et al. Aortic CrossSectional Area/Height Ratio and Outcomes in Patients with Bicuspid Aortic Valve and a Dilated Ascending Aorta. Circ Cardiovasc Imaging 2017;10:e006249.

35. Albornoz G, Coady MA, Roberts M, et al. Familial Thoracic Aortic Aneurysms and Dissections-Incidence, Modes of Inheritance, and Phenotypic Patterns. Ann Thorac Surg 2006;82:1400-5.

36. Farasat SM, Morrell CH, Scuteri A, et al. Do
Hypertensive Individuals Have Enlarged Aortic Root Diameters? Insights From Studying the Various Subtypes of Hypertension. Am J Hypertens 2008;21:558-63.

37. Stöwhas AC, Namdar M, Biaggi P, et al. The Effect of Simulated Obstructive Apnea and Hypopnea on Aortic Diameter and BP. Chest 2011;140:675-80.

38. Svensson LG, Kim KH, Lytle BW, et al. Relationship of aortic cross-sectional area to height ratio and the risk of aortic dissection in patients with bicuspid aortic valves. J Thorac Cardiovasc Surg 2003;126:892-3.

39. Agmon Y, Khandheria BK, Meissner I, et al. Is aortic dilatation an atherosclerosis-related process? Clinical, laboratory, and transesophageal echocardiographic correlates of thoracic aortic dimensions in the population with implications for thoracic aortic aneurysm formation. J Am Coll Cardiol 2003;42:1076-83.

40. Craiem D, El Batti S, Casciaro ME, Mousseaux E, et al. Age-related changes of thoracic aorta geometry used to predict the risk for acute type B dissection. Int J Cardiol 2017;228:654-60.

41. Tawfik AM, Sobh DM, Gadelhak B, et al. The effect of age and gender on tortuosity of the descending thoracic Aorta. Eur J Radiol 2019;110:54-9.

42. Komutrattananont $\mathrm{P}$, Mahakkanukrauh $\mathrm{P}, \mathrm{Das} \mathrm{S}$. Morphology of the human aorta and age-related changes: Anatomical facts. Anat Cell Biol 2019;52:109-14.

43. Angouras DC, Kritharis EP, Sokolis DP. Regional distribution of delamination strength in ascending thoracic aortic aneurysms. J Mech Behav Biomed Mater 2019;98:58-70.

44. Mori M, Bin Mahmood SU, Yousef S, et al. Prevalence of Incidentally Identified Thoracic Aortic Dilations: Insights for Screening Criteria. Can J Cardiol 2019;35:892-8.

45. Mariucci E, Donti A, Guidarini M, et al. Diagnostic Accuracy of Aortic Root Cross-sectional Area/Height Ratio in Children and Young Adults with Marfan and Loeys-Dietz Syndrome. Congenit Heart Dis 2016;11:276-82.

46. Acharya MN, Youssefi P, Soppa G, et al. Analysis of aortic area/height ratio in patients with thoracic aortic aneurysm and Type A dissection. Eur J Cardiothorac Surg 2018;54:696-701.

47. Masri A, Kalahasti V, Svensson LG, et al. Aortic CrossSectional Area/Height Ratio and Outcomes in Patients With a Trileaflet Aortic Valve and a Dilated Aorta. Circulation 2016;134:1724-37.

48. Zafar MA, Li Y, Rizzo JA, et al. Height alone, rather than body surface area, suffices for risk estimation in 
ascending aortic aneurysm. J Thorac Cardiovasc Surg 2018;155:1938-50.

49. Wojnarski CM, Svensson LG, Roselli EE, et al. Aortic Dissection in Patients With Bicuspid Aortic ValveAssociated Aneurysms. Ann Thorac Surg 2015;100:166673; discussion 1673-4.

50. Lang RM, Bierig M, Devereux RB, et al. Recommendations for chamber quantification: A report from the American Society of Echocardiography's guidelines and standards committee and the Chamber Quantification Writing Group, developed in conjunction with the European Association of Echocardiograph. J Am Soc Echocardiogr 2005; 18:1440-63.

51. Devereux RB, De Simone G, Arnett DK, et al. Normal limits in relation to age, body size and gender of twodimensional echocardiographic aortic root dimensions in persons > 15 years of age. Am J Cardiol 2012;110:1189-94.

52. Biaggi P, Matthews F, Braun J, et al. Gender, Age, and Body Surface Area are the Major Determinants of Ascending Aorta Dimensions in Subjects With Apparently Normal Echocardiograms. J Am Soc Echocardiogr 2009;22:720-5.

53. Sugawara J, Hayashi K, Yokoi T, et al. Age-Associated Elongation of the Ascending Aorta in Adults. JACC Cardiovasc Imaging 2008;1:739-48.

54. Campens L, Demulier L, Groote K De, et al. Reference Values for Echocardiographic Assessment of the Diameter of the Aortic Root and Ascending Aorta Spanning All Age Categories. Am J Cardiol 2014;114:914-20.

55. Blacher J, Safar ME. Large-artery stiffness, hypertension and cardiovascular risk in older patients. Nat Clin Pract Cardiovasc Med 2005;2:450-5.

56. Yamada H, Sakata N, Wada H, et al. Age-related distensibility and histology of the ascending aorta in elderly patients with acute aortic dissection. J Biomech 2015;48:3267-73.

57. Nienaber CA, Fattori R, Mehta RH, et al. Genderrelated differences in acute aortic dissection. Circulation 2004;109:3014-21.

58. Bons LR, Rueda-Ochoa OL, El Ghoul K, et al. Sexspecific distributions and determinants of thoracic aortic diameters in the elderly. Heart 2020;106:133-9.

59. Sokolis DP, Iliopoulos DC. Impaired mechanics and matrix metalloproteinases/inhibitors expression in female ascending thoracic aortic aneurysms. J Mech Behav Biomed Mater 2014;34:154-64.

60. Koullias GJ, Ravichandran P, Korkolis DP, et al. Increased tissue microarray matrix metalloproteinase expression favors proteolysis in thoracic aortic aneurysms and dissections. Ann Thorac Surg 2004;78:2106-10.

61. Morris DR, Biros E, Cronin O, et al. The association of genetic variants of matrix metalloproteinases with abdominal aortic aneurysm: A systematic review and metaanalysis. Heart 2014;100:295-302.

62. Boczar KE, Cheung K, Boodhwani M, et al. Sex Differences in Thoracic Aortic Aneurysm Growth: Role of Aortic Stiffness. Hypertension 2019;73:190-6.

63. Lindsay ME, Dietz HC. Lessons on the pathogenesis of aneurysm from heritable conditions. Nature 2011;473:308-16.

64. Wang L, Guo DC, Cao J, et al. Mutations in myosin light chain kinase cause familial aortic dissections. Am J Hum Genet 2010;87:701-7.

65. Guo DC, Pannu H, Tran-Fadulu V, et al. Mutations in smooth muscle -actin (ACTA2) lead to thoracic aortic aneurysms and dissections. Nat Genet 2007;39:1488-93.

66. Pannu H, Tran-Fadulu V, Papke CL, et al. MYH11 mutations result in a distinct vascular pathology driven by insulin-like growth factor 1 and angiotensin II. Hum Mol Genet 2007;16:2453-62.

67. Guo DC, Regalado E, Casteel DE, et al. Recurrent gainof-function mutation in PRKG1 causes thoracic aortic aneurysms and acute aortic dissections. Am J Hum Genet 2013;93:398-404.

68. Arslan-Kirchner M, Arbustini E, Boileau C, et al. Clinical utility gene card for: Hereditary thoracic aortic aneurysm and dissection including next-generation sequencing-based approaches. Eur J Hum Genet 2016;24:e1-5.

69. Renard M, Francis C, Ghosh R, et al. Clinical Validity of Genes for Heritable Thoracic Aortic Aneurysm and Dissection. J Am Coll Cardiol 2018;72:605-15.

70. O'Rourke MF, Nichols WW. Aortic diameter, aortic stiffness, and wave reflection increase with age and isolated systolic hypertension. Hypertension 2005;45:652-8.

71. Rayner BL, Goodman H, Opie LH. The chest radiograph: A useful investigation in the evaluation of hypertensive patients. Am J Hypertens 2004;17:507-10.

72. Savage DD, Henry WL, Eastman RC, et al. Echocardiographic assessment of cardiac anatomy and function in acromegalic patients. Am J Med 1979;67:823-9.

73. Virmani R, Avolio AP, Mergner WJ, et al. Effect of aging on aortic morphology in populations with high and low prevalence of hypertension and atherosclerosis: Comparison between occidental and Chinese communities. Am J Pathol 1991;139:1119-29.

74. Palmieri V, Bella JN, Arnett DK, et al. Aortic root 
dilatation at sinuses of Valsalva and aortic regurgitation in hypertensive and normotensive subjects: The Hypertension Genetic Epidemiology Network study. Hypertension 2001;37:1229-35.

75. Reutersberg B, Haller B, Mariss J, et al. Measurements After Image Post-processing Are More Precise in the Morphometric Assessment of Thoracic Aortic Aneurysms: An Intermodal and Intra-observer Evaluation. Eur J Vasc Endovasc Surg 2016;52:509-17.

76. Gaudric J, Politi MT, Fernández JM, et al. Calculation of the aortic arch angles from three-dimensional reconstructions of computed tomography scans: Comparison between an automated program and visual assessment. Comput Biol Med 2019;114:103440.

77. Alhafez BA, Truong VTT, Ocazionez D, et al. Aortic arch tortuosity, a novel biomarker for thoracic aortic disease, is increased in adults with bicuspid aortic valve. Int J Cardiol 2019;284:84-9.

78. Heuts S, Adriaans BP, Rylski B, et al. Evaluating the diagnostic accuracy of maximal aortic diameter, length and volume for prediction of aortic dissection. Heart 2020;106:892-7.

79. Hafiz AM, Medranda GA, Kakouros N, et al. Is intra-procedure three-dimensional transesophageal echocardiogram an alternative to preprocedure multidetector computed tomography for the measurement of the aortic annulus in patients undergoing transcatheter aortic valve replacement? Echocardiography 2017;34:1195-202.

80. Bons LR, Duijnhouwer AL, Boccalini S, et al. Intermodality variation of aortic dimensions: How, where and when to measure the ascending aorta. Int J Cardiol 2019;276:230-5.

81. Morganti S, Valentini A, Favalli V, et al. Aortic root 3D parametric morphological model from 2D-echo images. Comput Biol Med 2013;43:2196-204.

82. Ardellier FD, D'ostrevy N, Cassagnes L, et al. CT patterns of acute type A aortic arch dissection: Longer, higher, more anterior. Br J Radiol 2017;90:20170417.

83. Doyle BJ, Norman PE, Hoskins PR, et al. Wall Stress and Geometry of the Thoracic Aorta in Patients With Aortic Valve Disease. Ann Thorac Surg 2018;105:1077-85.

84. Hasegawa T, Oshima Y, Maruo A, et al. Aortic arch geometry after the Norwood procedure: The value of arch angle augmentation. J Thorac Cardiovasc Surg 2015;150:358-66.

85. Alberta HB, Takayama T, Smits TC, et al. Aortic Arch Morphology and Aortic Length in Patients with
Dissection, Traumatic, and Aneurysmal Disease. Eur J Vasc Endovasc Surg 2015;50:754-60.

86. Shirali AS, Bischoff MS, Lin HM, et al. Predicting the risk for acute type $\mathrm{B}$ aortic dissection in hypertensive patients using anatomic variables. JACC Cardiovasc Imaging 2013;6:349-57.

87. Guala A, Teixidó-Tura G, Rodríguez-Palomares J, et al. Proximal aorta longitudinal strain predicts aortic root dilation rate and aortic events in Marfan syndrome. Eur Heart J 2019;40:2047-2055.

88. Iliopoulos DC, Kritharis EP, Giagini AT, et al. Ascending thoracic aortic aneurysms are associated with compositional remodeling and vessel stiffening but not weakening in age-matched subjects. J Thorac Cardiovasc Surg 2009;137:101-9.

89. Della Corte A, Quarto C, Bancone C, et al. Spatiotemporal patterns of smooth muscle cell changes in ascending aortic dilatation with bicuspid and tricuspid aortic valve stenosis: Focus on cell-matrix signaling. J Thorac Cardiovasc Surg 2008;135:8-18.

90. Ou P, Celermajer DS, Raisky O, et al. Angular (Gothic) aortic arch leads to enhanced systolic wave reflection, central aortic stiffness, and increased left ventricular mass late after aortic coarctation repair: Evaluation with magnetic resonance flow mapping. J Thorac Cardiovasc Surg 2008;135:62-8.

91. De Caro E, Trocchio G, Smeraldi A, et al. Aortic Arch Geometry and Exercise-Induced Hypertension in Aortic Coarctation. Am J Cardiol 2007;99:1284-7.

92. Ou P, Mousseaux E, Celermajer DS, Pedroni E, et al. Aortic arch shape deformation after coarctation surgery: Effect on blood pressure response. J Thorac Cardiovasc Surg 2006;132:1105-11.

93. Ou P, Bonnet D, Auriacombe L, et al. Late systemic hypertension and aortic arch geometry after successful repair of coarctation of the aorta. Eur Heart J 2004;25:1853-9.

94. Morris SA, Orbach DB, Geva T, et al. Increased vertebral artery tortuosity index is associated with adverse outcomes in children and young adults with connective tissue disorders. Circulation 2011;124:388-96.

95. Franken R, El Morabit A, De Waard V, et al. Increased aortic tortuosity indicates a more severe aortic phenotype in adults with Marfan syndrome. Int J Cardiol 2015;194:7-12.

96. Kleinstreuer C, Li Z. Analysis and computer program for rupture-risk prediction of abdominal aortic aneurysms. Biomed Eng Online 2006;5:19. 
97. Fillinger MF, Raghavan ML, Marra SP, et al. In vivo analysis of mechanical wall stress and abdominal aortic aneurysm rupture risk. J Vasc Surg 2002;36:589-97.

98. Vande Geest JP, Di Martino ES, Bohra A, et al. A biomechanics-based rupture potential index for abdominal aortic aneurysm risk assessment: Demonstrative application. Ann N Y Acad Sci 2006;1085:11-21.

99. Fillinger MF, Marra SP, Raghavan ML, et al. Prediction of rupture risk in abdominal aortic aneurysm during observation: Wall stress versus diameter. J Vasc Surg 2003;37:724-32.

100.Martin C, Sun W, Pham T, et al. Predictive biomechanical analysis of ascending aortic aneurysm rupture potential.

Cite this article as: Luan J, Mao L, Zhu Z, Fu W, Zhu T. New indicators for systematic assessment of aortic morphology: a narrative review. J Thorac Dis 2021;13(1):372-383. doi: 10.21037/ jtd-20-2728
Acta Biomater 2013;9:9392-400.

101. Vorp DA, Schiro BJ, Ehrlich MP, et al. Effect of aneurysm on the tensile strength and biomechanical behavior of the ascending thoracic aorta. Ann Thorac Surg 2003;75:1210-4.

102. Okamoto RJ, Xu H, Kouchoukos NT, et al. The influence of mechanical properties on wall stress and distensibility of the dilated ascending aorta. J Thorac Cardiovasc Surg 2003;126:842-50.

103. Black KM, Masuzawa A, Hagberg RC, et al. Preliminary Biomarkers for Identi fi cation of Human Ascending Thoracic Aortic Aneurysm. J Am Heart Assoc 2013;2:e000138. 